$\underline{\text { Please cite this paper as: }}$

Diego Magaldi, ${ }^{1}$ Maria Ulfa, ${ }^{2}$ Mai-Phuong Nghiêm, ${ }^{3}$ Gjergji Sini, ${ }^{1}$ Fabrice Goubard, ${ }^{1}$ Thierry Pauporté, ${ }^{2 *}$ and Thanh-Tuân Bui ${ }^{1 *}$

\title{
Hole transporting materials for perovskite solar cells: molecular versus polymeric carbazole-based derivatives
}

J. Mater. Sci. 2020, 55, 4820-4829.

DOI: $10.1007 / \mathrm{s} 10853-019-04342-6$

${ }^{1}$ Laboratoire de Physicochimie des Polymères et des Interfaces (LPPI), Université de Cergy-Pontoise, 5 mail Gay Lussac, 95000 Neuville-sur-Oise, France

${ }^{2}$ Chimie ParisTech, PSL Research University, CNRS, Institut de Recherche de Chimie Paris (IRCP), UMR8247, 11 rue P. et M. Curie, F-75005 Paris, France.

${ }^{3}$ Plateforme Microscopies et Analyses, Fédération Institut des Matériaux (iMAT), Université de CergyPontoise, Rue Descartes, 95000 Neuville-sur-Oise, France.

Corresponding authors: thierry.pauporte@chimie-paristech.fr (T.P.), tbui@u-cergy.fr(T.-T.B.)

\begin{abstract}
:
Designing organic hole transporting materials (HTMs) for stable perovskite photovoltaic devices remains a great challenge. Herein, we have prepared two small carbazole-based HTMs bearing a polymerizable double bond and one of the corresponding polymers. All compounds can be easily synthetized by a short procedure from largely available commercial products. These compounds have thermal, morphological, optical and electrochemical properties suitable for an application in perovskite solar cells. The side chains at the $N$-positon on the carbazole have a negligible influence on the opto-electrochemical properties. However, the thermal properties differ largely between the monomer and its corresponding polymer. While these materials have the same photovoltaic performance, the polymeric HTM led to more stable devices. This illustrates the higher thermal stability of polymeric HTM versus its corresponding monomer.
\end{abstract}

Keyword: carbazole, hole transporting material, perovskite solar cell, polymer

\section{Introduction}


In recent years, the development of carbazole-based functional materials for emerging technological applications has received considerable interest. Carbazole offers very diverse chemistry enabling the design of different kind of functional materials having interesting optical and electrochemical properties, good charge transport, high thermal and morphological stability. ${ }^{1-9}$ A huge number of molecular and polymeric carbazole derivatives have been developed for photovoltaics, especially for the emerging perovskite solar cells (PSCs). ${ }^{10}$ PSCs have become the most promising renewable energy technology due to their high light-to-electricity conversion efficiency, their solution processability, low cost and possible large scale production. ${ }^{11}$ In PSC technology, the hole-transporting materials (HTM) and electron-transporting materials (ETM) implemented for selective contacts and serving for electron and hole extraction are important. ${ }^{12}$ HTM and ETM having high charge transport properties with accurate frontier energy levels ( $\mathrm{E}_{\text {HOMO }}$ and $\mathrm{E}_{\mathrm{LUMO}}$ ) compatible with perovskite valence band maximum (VBM) and conduction band minimum (CBM) bands are key for achieving high efficiency. However, the accurate design of efficient HTMs and ETMs for PSC devices, remains a great challenge. An ideal HTM must fulfil some general requirements to work efficiently in PSCs. Its $\mathrm{E}_{\mathrm{HOMO}}$ must be compatible with the VBM energy of the perovskite in order to provide the suitable driving force for charge transfer. Furthermore, its $E_{\text {LUMO }}$ should be significantly higher than that of the CBM of the perovskite absorbers to exhibit electron-blocking properties. Sufficient hole mobility, excellent thermal, morphological and photochemical stability, as well as a high hydrophobic property to protect the perovskite materials from moisture are also important key properties. Organic HTMs can be essentially divided into two subclasses depending on their molecular weights: molecular and polymeric HTMs. ${ }^{13}$ While molecular HTMs feature well-defined molecular weight and structure with high synthetic reproducibility and easy purification, the polymer ones offer important advantages in terms of processability, thermal and mechanical stability, and higher intrinsic hole mobility. ${ }^{14-17}$ A huge number of organic HTM have been reported in the literatures. ${ }^{2,4,5,18-23}$ Structurally, most of them contain electronrich tertiary aromatic amine function. ${ }^{24}$ Among the different HTM families, carbazole derivatives occupy an important place, especially the materials containing the 3,6-bis(di(4-methoxyphenyl)aminyl)carbazole building block. ${ }^{25}$ The methoxy group effectively tune the solubility as well as the optoelectrochemical properties of targeted molecules and it provides a good interaction with perovskite materials' surface, notably with $\mathrm{Pb}$ (II) ion. ${ }^{26}$ Initially we employed this building block to develop HTM for solid state dyesensitized solar cells ${ }^{2}$ prior to successfully applied them in PSCs. ${ }^{19}$ Recently, we employed this building block to design a dendritic molecular HTM which took advantages of both molecular and polymeric materials. ${ }^{27}$ Comparative study of this molecule with its simple model clearly showed that this HTM designing strategy could give PSC device with higher stability. ${ }^{19,27,28}$ In continuity with this work, in the 
present study, the same building block was used to design novel polymerizable molecular HTMs (DM1 and DM2, Scheme 1).
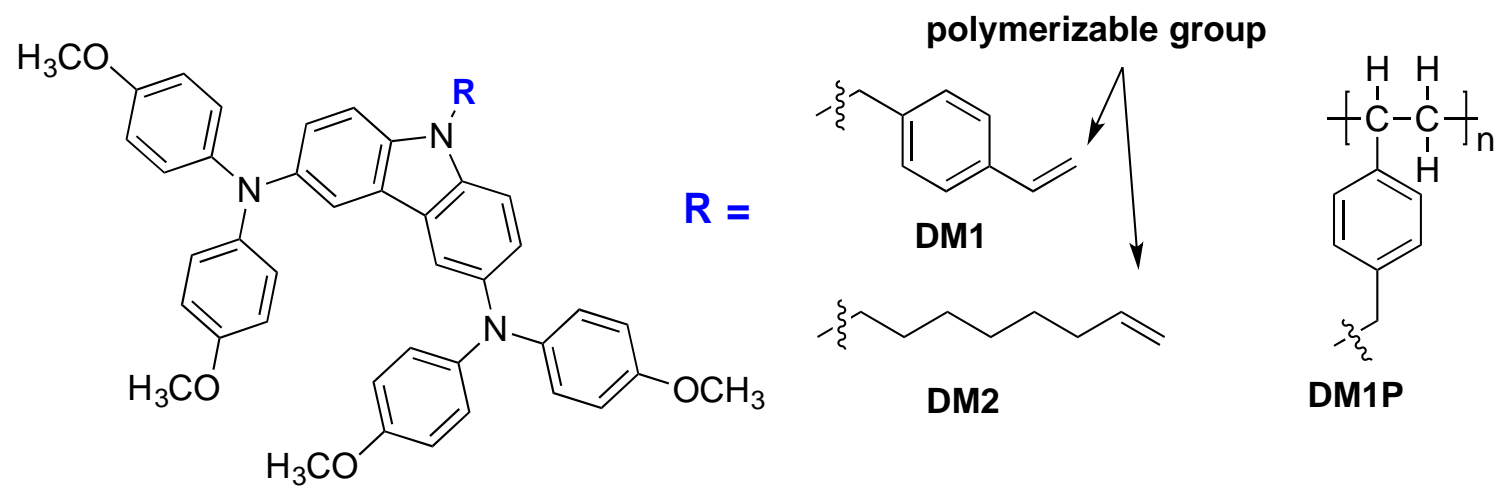

\section{Scheme 1. Structure of studied HTMs}

DM1 could be successfully transformed into its corresponding polymer (DM1P, Scheme 1). We thus made a comparative study of the molecular HTMs bearing a polymerizable double bond function and its corresponding polymeric counterparts and evaluated the devices performance and operation stability.

\section{Results and discussion}

\subsection{Materials synthesis}

DM1 and DM2 were synthetized using the synthetic route given in Scheme 2 and already employed in our previous works. ${ }^{2,29}$ Briefly, 3,6-dibromocarbazole reacts with alkyl halide or benzyl halide in basic medium leading to $N$-substituted carbazoles (1-2). 1 and 2 are then subjected to a twofold Pd-catalyzed amination with 4,4'-dimethoxydiphenylamine, leading to the final products (DM1-2) in good yields. The detailed description and the analytical analysis of DM1 and DM2 has been recently reported in a separate article focused on the photopolymerization application. ${ }^{29}$ 

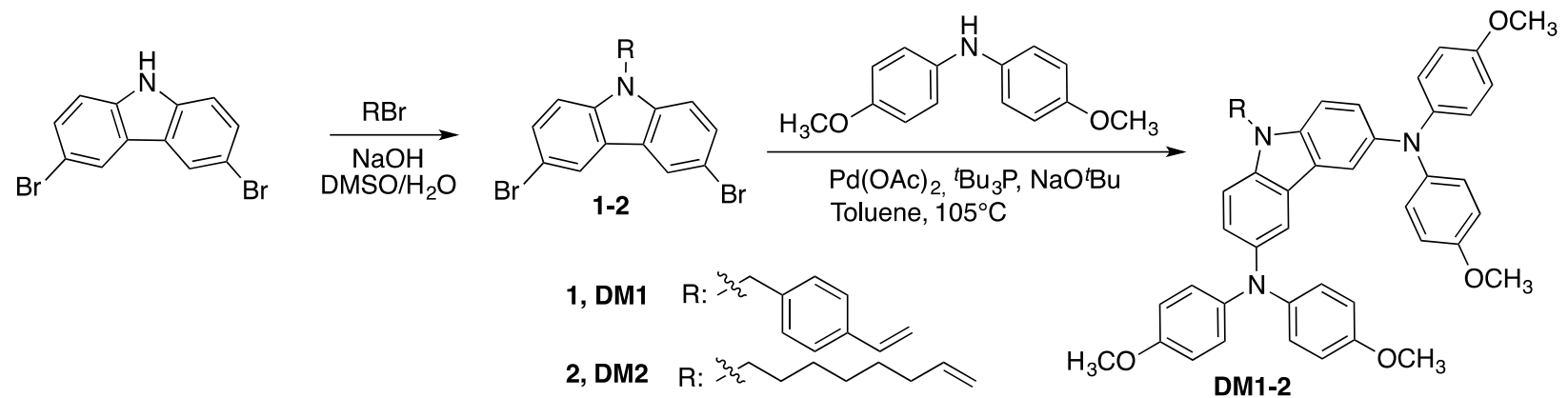

Scheme 2. Synthesis of DM1 and DM2

In the next step, we attempted to convert DM1 and DM2 into their corresponding polymers. Different classic alkene polymerization conditions were implemented such as radical (AIBN and BPO) and anionic (tert-butyl lithium, $\mathrm{NaOH}$ ) ones in different solvents (toluene, cyclohexanone, DMF) but they only led to traces of polymers. Finally, we found that during the synthesis of DM1, if chloroform is added into the reaction medium in the amination step, a polymer (called DM1P) is spontaneously formed. DM1P was also formed when ${ }^{t} \mathrm{BuONa}$ was added into a solution of purified DM1 dissolved in a mixture of $\mathrm{CHCl}_{3} /$ toluene at room temperature and let to react under stirring for 4 hours. The solvents were then removed to the saturation point and the product was added into $\mathrm{MeOH}$ to precipitate the polymer. In both cases, yellow amorphous polymers were obtained in $60-80 \%$ of yield. We believe that DM1P is formed by a chain transfer reaction catalyzed by the chloroform and the strong basic conditions. ${ }^{30-35}$ GPC analysis showed that DM1P had an average molecular weight of $c a .43 \mathrm{kDa}(\mathrm{PDI}=2.19)$. All of these mentioned polymerization methods have been also applied to DM2. However, no polymer formation was observed which could be explained by the lack of the stability of the intermediate radicals due to the absence of a conjugated aromatic ring like the case of DM1. All materials (DM1, DM2, DM1P) were well-soluble in common organic solvent, rending them suitable for solution processing.

\subsection{Structural, thermal, and morphological properties}

The DM1P polymer was studied by density functional theory (DFT) calculations using the Gaussian $09^{36}$ suite of programs. Ground state geometries of DM1P series were fully optimized starting from two different initial arrangements between the median axes of successive pending groups, $120^{\circ}$ and $180^{\circ}$ arrangements. The $\mathrm{wB}^{\mathrm{B}} 9 \mathrm{WD} \mathrm{W}^{37}$ functional was used for these calculations in conjunction with the 6$31 \mathrm{G}(\mathrm{d}, \mathrm{p})$ basis set. 


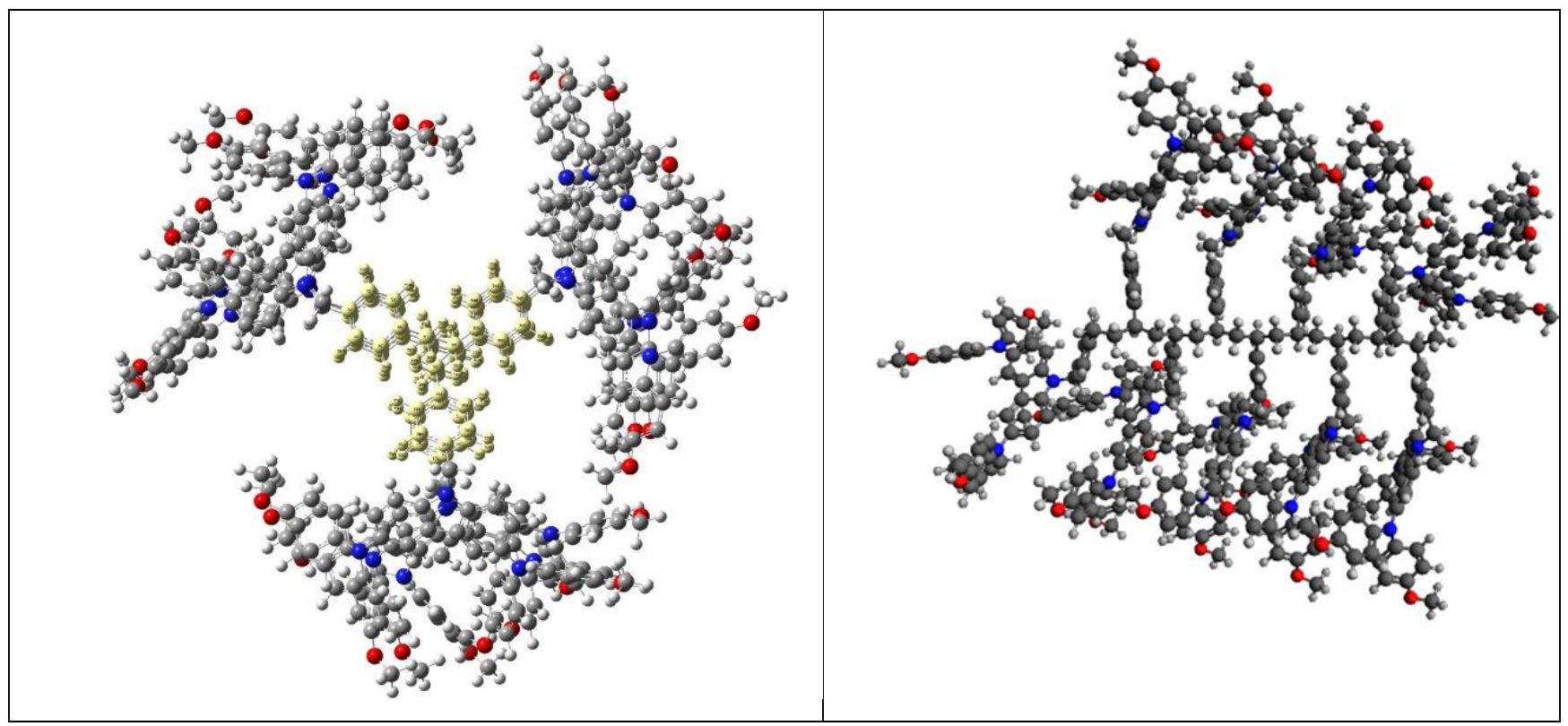

Figure 1. DM1P $120^{\circ}$ "triangular" conformation (left) and $180^{\circ}$ conformation (right)

Representations of the two structures are shown in Figure 1 . Both $120^{\circ}$ and $180^{\circ}$ conformations have the same number of bis(diphenylaminyl)-carbazole units (nine in total). The di(4-methoxyphenyl)aminyl groups substituted over carbazole are closer to each other in a $180^{\circ}$ conformation, making this structure less probable to occur due to steric hindrance as compared to $120^{\circ}$ conformation where molecules have more free space to arrange in a triangular conformation. Given the overcrowded structure of this polymer, for a clearer view, the non-conductive polystyrene is highlighted in yellow fragments in the $120^{\circ}$ triangular conformation. Whatever the stability order between the two structures, a mixture of both conformations should be found in the amorphous state. The dominant conformer being very probably the one with triangular- $120^{\circ}$ disposition.

Thermogravimetric analysis (TGA) and differential scanning calorimetry (DSC) experiments were conducted to examine the thermal properties of the novel carbazole derivatives. Figure 2 shows the TGA curves of the different compounds while all DSC curves are given in the ESI (Figures S 1, 2, 3). Thermal data are gathered in Table 1. All these compounds were found thermally stable with a thermal decomposition temperatures $\left(\mathrm{T}_{\mathrm{d}}\right)$ higher than $400^{\circ} \mathrm{C}$ which are high enough for practical applications. 


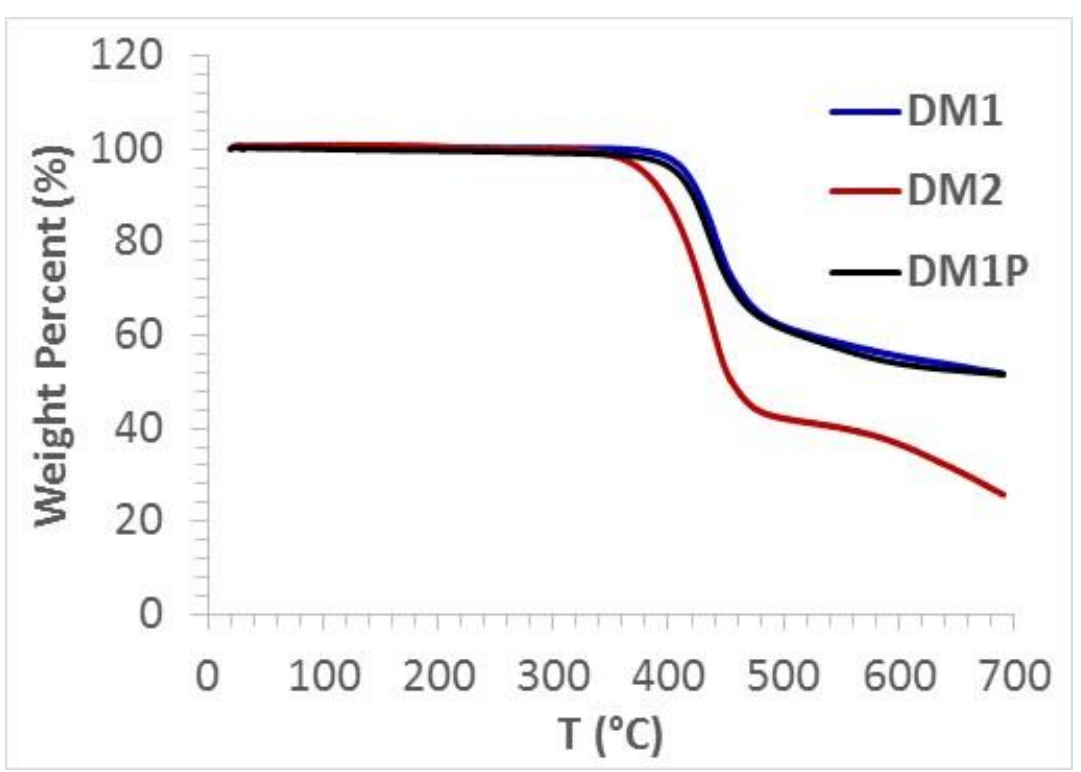

Figure 2. TGA curves of DM1, DM2 and DM1P

When subjected to DSC analyses, the monomeric compounds (DM1, DM2) exhibited different behavior from the polymer (DM1P) one. In the first heating cycle of DSC analysis (Fig. S1 in ESI), DM1 exhibited a glass-transition at $\mathrm{T}_{\mathrm{g}}=61^{\circ} \mathrm{C}$. At higher temperature, an exothermic transition centered at $150{ }^{\circ} \mathrm{C}$ was observed assigned to the thermal curing of the molecule at its styrene moiety forming higher molecular weight oligomers. The second heating cycle confirmed this assignment with the loss of the transition at low temperature and a new glass transition observed at $\mathrm{T}_{\mathrm{g}}=115^{\circ} \mathrm{C}$. The latter is ascribed to the glass transition of the thermally formed oligomers. This is in good agreement with the behavior of the corresponding chemically synthetized polymer (DM1P, Fig. S2 in ESI, T $=186^{\circ}$ C). DM2 (Fig. S3 in ESI) had a similar thermal behavior to DM1 with the first endothermic transition at $59.5^{\circ} \mathrm{C}$ and the second small exothermic peak centered at $150^{\circ} \mathrm{C}$. However, its second heating cycle shows only the glass transition of the monomer $\left(\mathrm{T}_{\mathrm{g}}=50^{\circ} \mathrm{C}\right)$. Unfortunately, we could not chemically synthetize the corresponding polymer from DM2 by chemical method for comparison purpose. The $\mathrm{T}_{\mathrm{g}}$ of DM1 and DM2 are slightly lower than that of similar molecules without double bonds in the side chain at the $\mathrm{N}$ position of carbazole core. ${ }^{2}$ This is in good agreement with the fact that the longer side chain makes molecules more flexible and lower their $\mathrm{T}_{\mathrm{g}}$.

As expected for amorphous organic materials, all compounds showed smooth surfaces via atomic force microscopy (AFM) analysis. The AFM images are given in Figure 3. All HTM were doped with tertbutylpyridine and LiTFSI to mimic the condition in PSC application. 

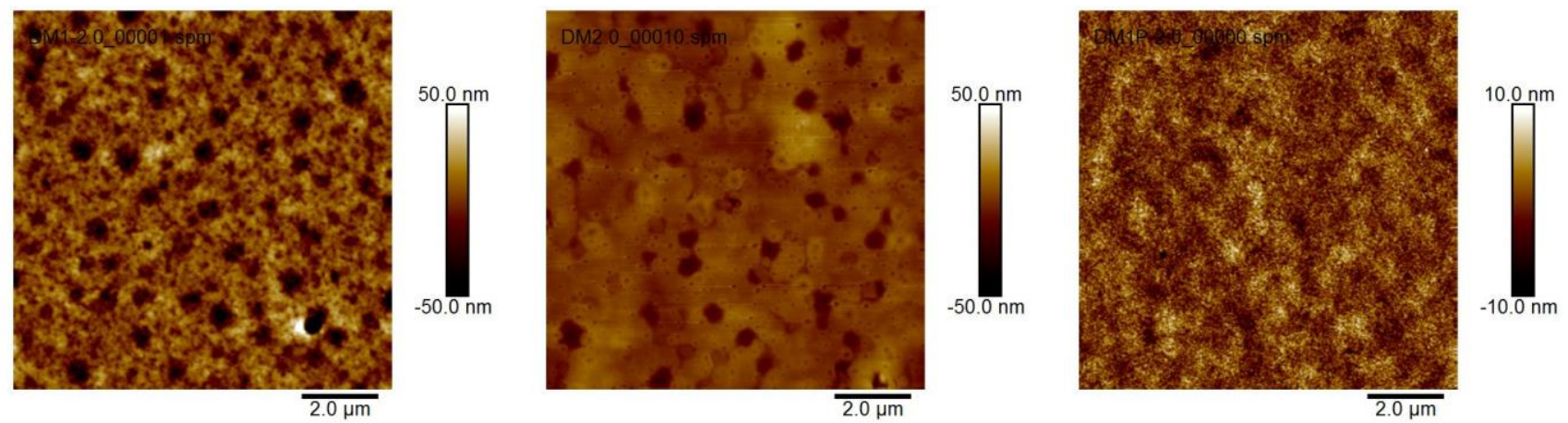

Figure 3. Atomic force microscopy (AFM) images of the HTMs (A) DM1, (B) DM2 and (C) DM1P thin films (doped with tert butyl pyridine and LiTFSI). Surface roughness (RMS): DM1 $(12.9 \mathrm{~nm})$, DM2 $(6.1 \mathrm{~nm})$, DM1P $(2.3 \mathrm{~nm})$

The surface roughness was estimated at $12.9 \mathrm{~nm}$ for DM1, 6.1 $\mathrm{nm}$ for DM2, while the polymer DM1P HTM layer was the smoothest at $2.3 \mathrm{~nm}$. These smooth surfaces are expected to provide perfect HTM/perovskite contact and thus to facilitate the hole transfer from perovskite to HTM and protect the perovskite absorber layer against moisture.

\subsection{Optical and electrochemical properties}

The optical properties of the three materials were examined in dilute solution and in the thin solid film state. The spectra are disclosed in Figure 4 and the related data are gathered in Table 1. 


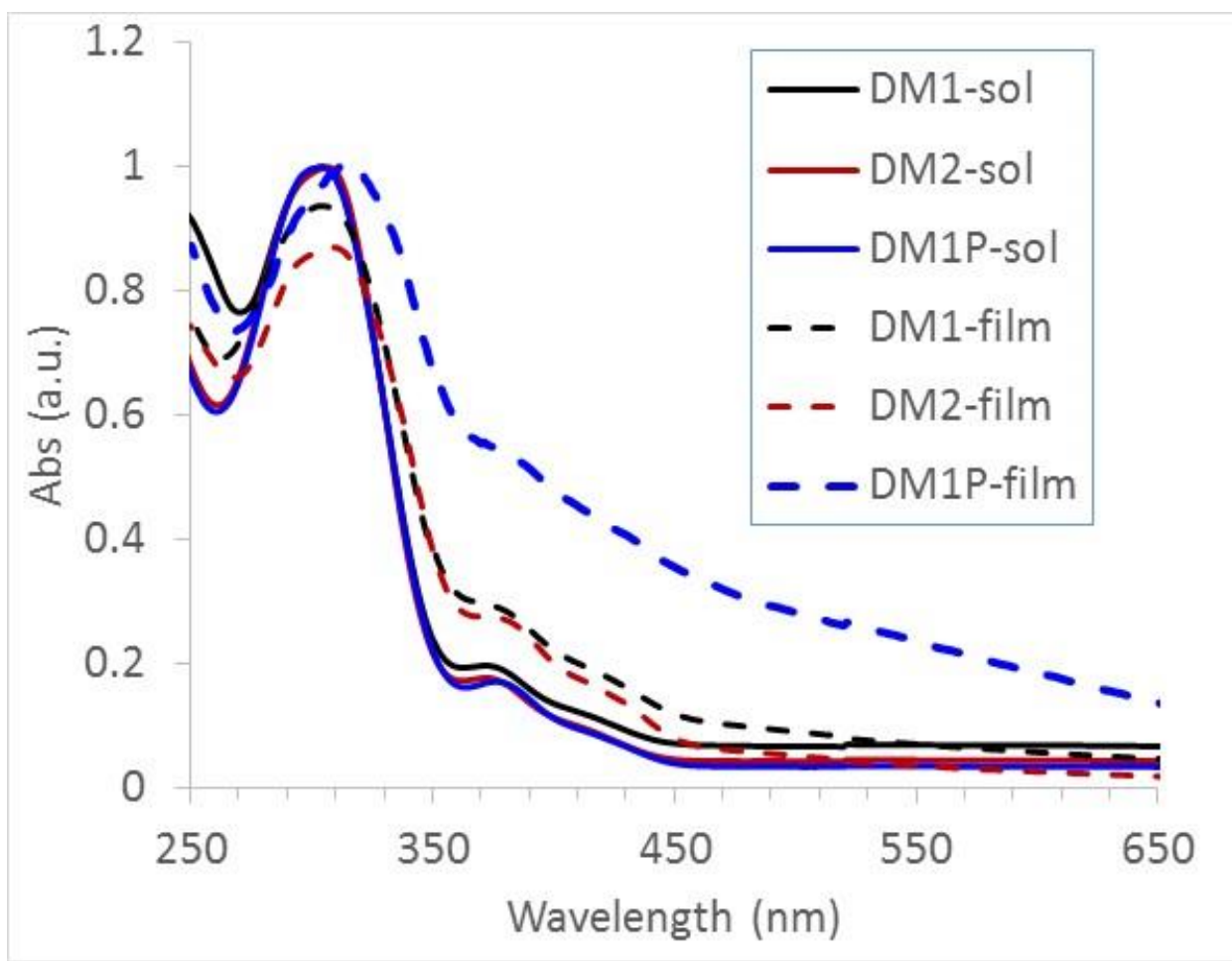

Figure 4. UV/Vis absorption spectra of DM1, DM2 and DM1P in dilute $\mathrm{CH}_{2} \mathrm{Cl}_{2}$ solutions and in thin film.

In dilute solution, all materials have identical absorption behaviour with a strong absorption band located in the UV spectral domain centred at $c a$. 300-320 nm. Another weaker absorption band is observed at longer wavelength, in the UV-near visible region (350-450 nm). Obviously, all compounds, including the polymer DM1P, have the same optical behaviour as the model compound without double bonds in the side chain at the $N$-position of the carbazone, which is typical for bisdiphenylaminylcarbazole derivatives. ${ }^{2}$ In our previous study, DFT calculations showed that the side chain at the N-position of the carbazole ring had no effect on the optical properties of these derivatives. ${ }^{2}$ The polymerization did not affect the optical properties of the target compound as it created a saturated polystyrene polymer backbone. The spectra recorded for thin films are identical to that recorded in dilute solution. It indicates no aggregation in the solid state. This could be attributed to the tridimentional bulky structures of 3,6bisdiarylamine substituted carbazole derivatives. The optical bandgap was determined from the onset of the absorption spectrum in the solid state and the data is given in Table 1. These values are somewhat smaller than that of the Spiro-OMeTAD $\left(\mathrm{E}_{\mathrm{g}}=3.0 \mathrm{eV}\right) .^{2}$

The redox behavior of carbazole materials were examined by cylic voltammetry. In combination with optical bandgap, the redox potentials were used to estimate their $\mathrm{E}_{\text {HOMO }}$ and $\mathrm{E}_{\mathrm{LUMO}}$. $\mathrm{E}_{\mathrm{HOMO}}$ were estimated from the oxidation potential by using the ferrocene $(\mathrm{Fc})$ ionization potential value as reference $\left(4.8 \mathrm{eV} v s\right.$. vacuum $\left.^{38,39}\right)$. As expected, the nature of the side chain at the $N$-position of the carbazole and 
the polymerization did not significantly influence the electrochemical redox properties of final materials. In Figure 5, the cyclic voltammogram of all materials are identical, showing multiple oxidation processes while no reduction process was observed in the cathodic scan. The first reversible oxidation potential could be attributed to the formation of radical cation of the carbazole moiety. DM1 exhibits an oxidation potential onset of $-0.20 \mathrm{~V} / \mathrm{Fc} / \mathrm{Fc}^{+}$, which is nearly identical to that of the DM2 (-0.16 V) and DM1P ($0.15 \mathrm{~V})$. These oxidation potentials are very close to that reported for similar molecules without polymeriable double bonds and that of Spiro-OMeTAD measured under the same conditions. ${ }^{2}$ This confirms the trend that the side chains at $N$-position of carbazole have a negligible effect on the electrochemical properties of the targeted compounds. EHOMO was estimated from the first oxidation potential onset while $\mathrm{E}_{\mathrm{LUMO}}$ was estimated from the $\mathrm{E}_{\mathrm{HOMO}}$ and the optical bandgap. The $\mathrm{E}_{\mathrm{HOMO}}$ values of DM1, DM2 and DM1P are - 4.60, - 4.64, and - $4.65 \mathrm{eV}$ respectively. 


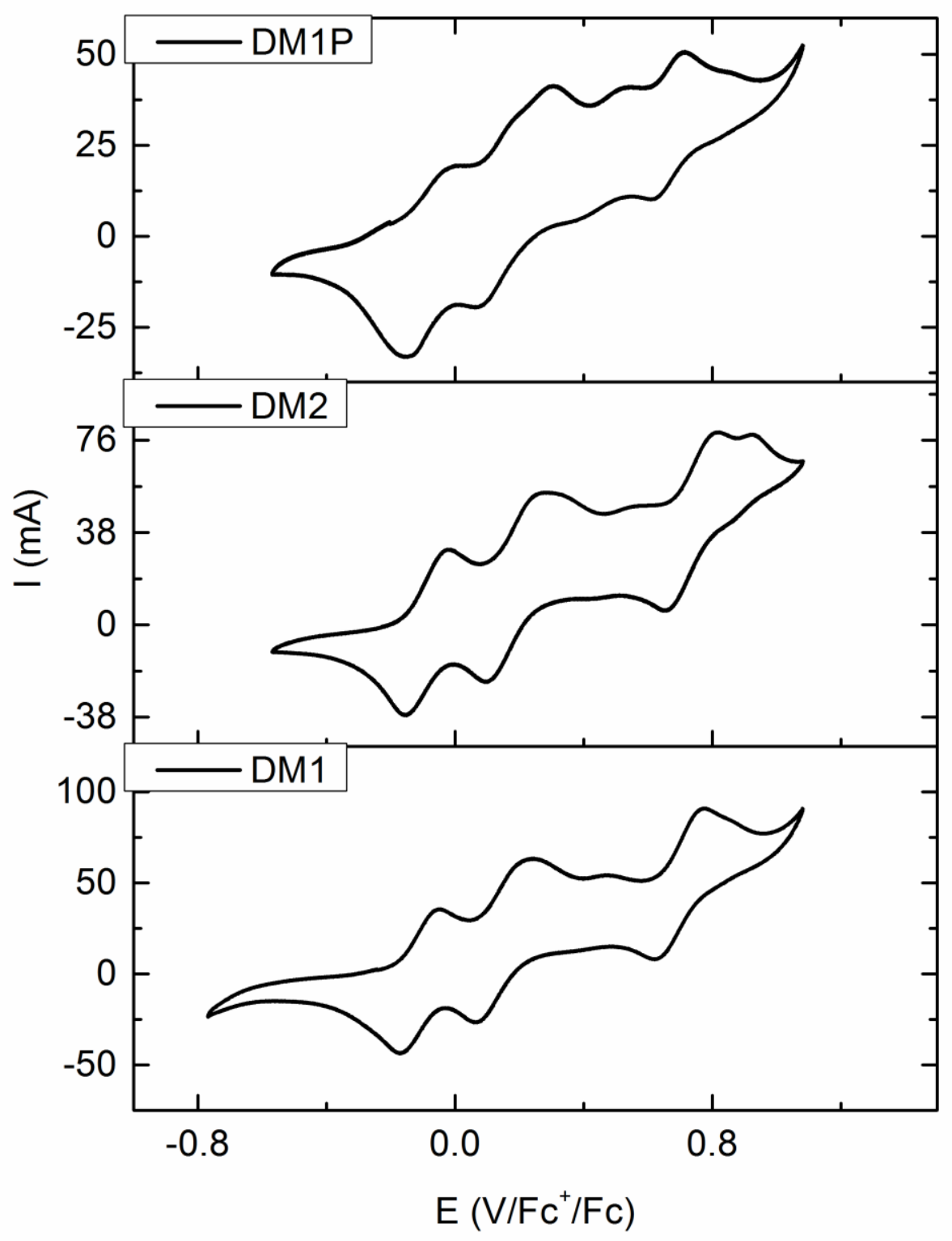

Figure 5. CV of DM1, DM2 and DM1P in 0.01M TBAPF $/ \mathrm{CH}_{2} \mathrm{Cl}_{2}$ solution and scan rate was $100 \mathrm{mV}$ $\mathrm{S}^{-1}$.

From the $\mathrm{E}_{\text {HOMo }}$ and the optical bandgap, corresponding $\mathrm{E}_{\mathrm{LUMO}}$ were estimated and reported in Table 1. These $\mathrm{E}_{\mathrm{HOMO}}$ and $\mathrm{E}_{\mathrm{LUMO}}$ suggest that all compound could be suitable for use as HTM in the PSC, ensuring good hole transfer and the electron blocking at the interface. PSCs employing these HTMs have been fabricated and their photovoltaic characteristics are discussed in the next section. 
Table 1. Thermal, optical and electrochemical properties of the investigated HTM's DM1, DM2 and DM1P.

\begin{tabular}{|c|c|c|c|c|c|c|c|c|}
\hline Compound & $\mathrm{T}_{\mathrm{d}}[\mathrm{a}]$ & $\mathrm{T}_{\mathrm{g}}[\mathrm{b}]$ & $\lambda_{\max }[\mathrm{c}]$ & $\lambda_{\text {onset }}[\mathrm{c}]$ & $\mathrm{E}_{\mathrm{gap}}[\mathrm{d}]$ & $\mathrm{E}_{\mathrm{ox}}{ }^{\text {onset }}[\mathrm{e}]$ & $\mathrm{E}_{\mathrm{HOMO}}[\mathrm{f}]$ & $\mathrm{E}_{\mathrm{LuMO}}[\mathrm{g}]$ \\
\hline & ${ }^{\circ} \mathrm{C}$ & ${ }^{\circ} \mathrm{C}$ & $\mathrm{nm}$ & $\mathrm{nm}$ & $\mathrm{eV}$ & $\mathrm{V} / \mathrm{Fc} / \mathrm{Fc}^{+}$ & $\mathrm{eV}$ & $\mathrm{eV}$ \\
\hline DM1 & 415 & 61 & 305,375 & 443 & 2.80 & -0.20 & -4.60 & -1.80 \\
\hline DM2 & 414 & 50 & 307,372 & 444 & 2.80 & -0.16 & -4.64 & -1.84 \\
\hline DM1P & 405 & 186 & 309,382 & 454 & 2.73 & -0.15 & -4.65 & -1.92 \\
\hline
\end{tabular}

[a]Obtained from TGA measurements. [b]Obtained from DSC measurements. [c] Measured in $\mathrm{CH}_{2} \mathrm{Cl}_{2}$ solution at concentration of $1 \mathrm{mM}$. [d] $E_{\mathrm{g}}^{\text {opt }}=h \mathrm{c} / \lambda_{\text {onset }}=1240 / \lambda_{\text {onset }}(\mathrm{eV})$. [e] in $\mathrm{CH}_{2} \mathrm{Cl}_{2}$ solution containing $\mathrm{TBAPF}_{6}$ as supporting electrolyte $(0.1 \mathrm{M})$, scan rate $100 \mathrm{mV} . \mathrm{s}^{-1} \cdot[\mathrm{f}] \mathrm{E}_{\text {Hомо }}=-\left(4.8+\mathrm{E}_{\text {ox }}{ }^{\text {onset }}\right)(\mathrm{eV}) .[\mathrm{g}] \mathrm{E}_{\text {LUMO }}=\mathrm{E}_{\text {HOMO }}+\mathrm{E}_{\text {gap }}(\mathrm{eV})$

\subsection{Photovoltaic properties}

The new carbazole compounds were tested for an application as HTM in PSC with methylammonium lead iodide $\left(\mathrm{CH}_{3} \mathrm{NH}_{3} \mathrm{PbI}_{3}\right)$ as the hybrid perovskite compound. ${ }^{37}$ We used the same optimized device structure as we reported earlier with the optimized thickness of the HTM layer of ca. $200 \mathrm{~nm}$ in comparison to $150 \mathrm{~nm}$ of Spiro-OMeTAD. ${ }^{28}$ The general device structure used in this work and the energy level alignment of different device components are shown in Figure 6.

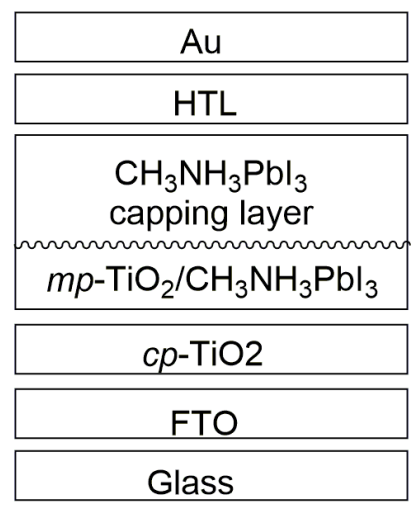

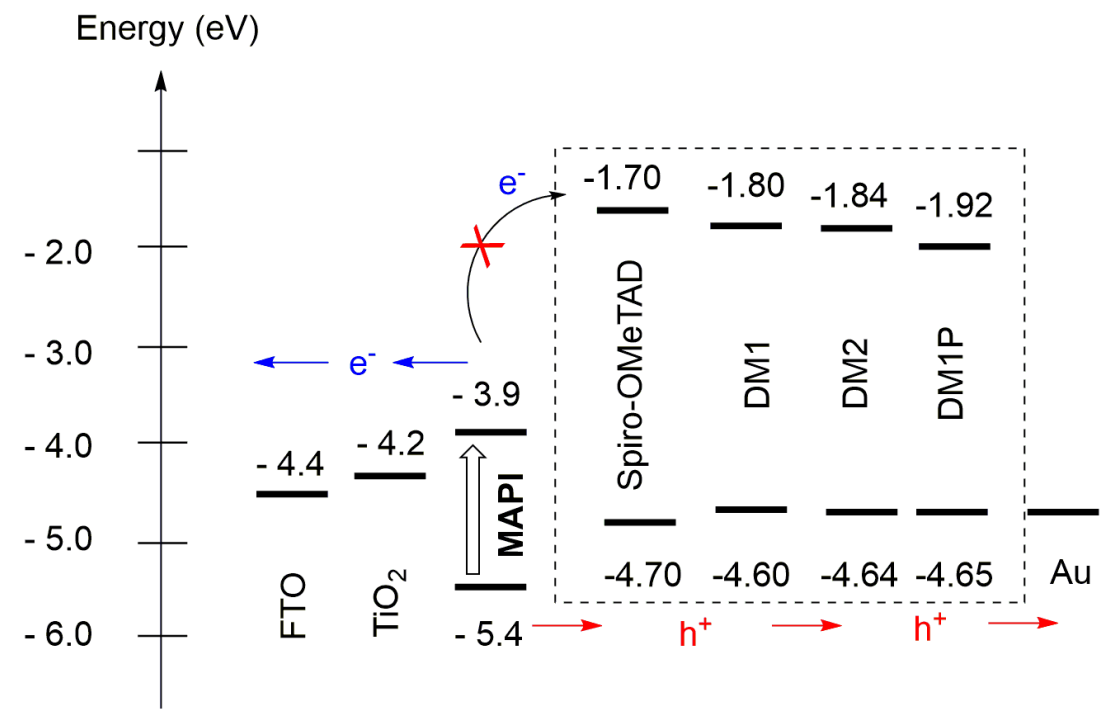

Figure 6. Schematic presentation of PSC device structure (left) and the energy alignment of its different components (right)

The two-step perovskite deposition method was employed as fully described in our previous paper. ${ }^{40}$ The photovoltaic characteristics of the best cells together with average values for each HTM are gathered in Table 2. They are compared to benchmark Spiro-OMeTAD cells produced during the same batches. The $J-V$ curves of the best devices are given in Figure 7 . The maximum efficiency was measured for the 
DM1 HTM at 12.2\% and it was approaching 12\% for DM2. DM1P cells had a slightly higher PCE with a maximum at $13.24 \%$. However, the averaged PCE values of all HTM were nearly identical with the $\mathrm{V}_{\mathrm{oc}}$ of all devices being close. The best result with DM1 compared to DM2 is due to the higher FF parameter. It is also noteworthy that the DM2 cells exhibited the highest $\mathbf{J}_{\mathrm{sc}}$, with values close to that of the Spiro-OMeTAD cells (Table 2). The cells with the polymer HTM had slightly ameliorated performances. Without dopant, the efficiency of DM1P cells was very low (below $0.7 \%$ ); their $J$ - $V$ curves were typical of highly resistive devices and problems of charge injection and transport occurred. For DM1P HTM, without doping, the device suffered from a very low FF that can be attributed to the low HTM conductivity and therefore high charge transport resistances. For all the carbazole HTMs, the $\mathrm{V}_{\mathrm{oc}}$ of the cells were lower than the Spiro-OMeTAD ones. It suggests the occurrence of more recombinations at the perovskite/HTM interface.

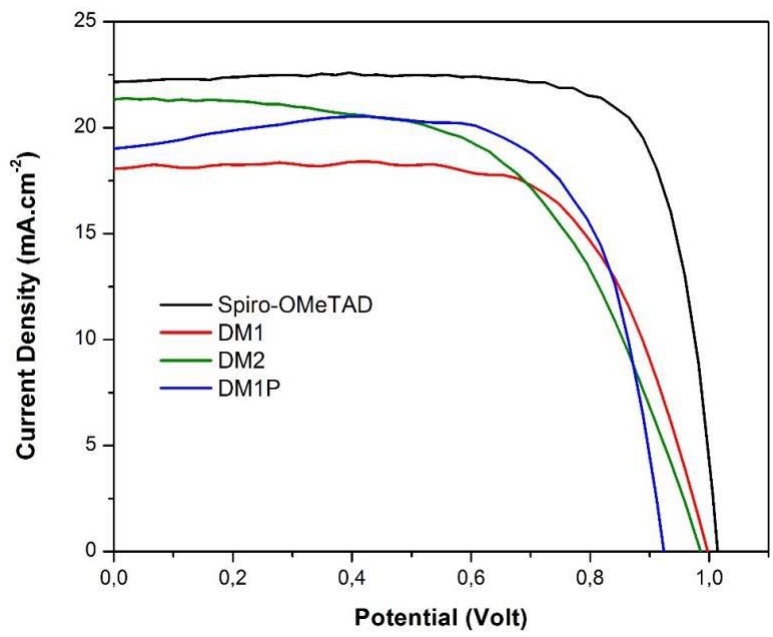

Figure 7. $J$ - $V$ reverse scan curves of the best PSC devices reported in this work

Table 2. Photovoltaic parameters of the best device of each HTM. The values in parenthesis are average values.

\begin{tabular}{|l|l|l|l|l|l|}
\hline HTM & Scan direction & $\mathrm{V}_{\mathrm{oc}}(\mathrm{V})$ & $\mathrm{J}_{\mathrm{sc}}\left(\mathrm{mA}_{\mathrm{c}} \mathrm{cm}^{-2}\right)$ & $\mathrm{FF}(\%)$ & $\eta(\%)$ \\
\hline \multirow{2}{*}{ DM1 } & Reverse & $0.99(0.97)$ & $17.99(20.69)$ & $68.4(58.18)$ & $12.26(11.63)$ \\
\cline { 2 - 6 } & Forward & $0.99(0.97)$ & $18.6(20.92)$ & $59.65(49.89)$ & $11.08(10.07)$ \\
\hline \multirow{2}{*}{ DM2 } & Reverse & $0.97(0.97)$ & $21.31(21.42)$ & $56.18(54.12)$ & $11.73(11.32)$ \\
\cline { 2 - 6 } & Forward & $0.97(0.96)$ & $21.02(21.16)$ & $48.00(43.98)$ & $9.84(8.97)$ \\
\hline \multirow{2}{*}{ DM1P } & Reverse & $0.92(0.91)$ & $18.98(15.95)$ & $75.53(76.04)$ & $13.24(11.09)$ \\
\cline { 2 - 6 } & Forward & $0.95(0.93)$ & $16.94(17.98)$ & $48.01(42.62)$ & $7.70(7.18)$ \\
\hline \multirow{2}{*}{ Spiro-OMeTAD } & Reverse & $1.01(1.01)$ & $22.15(21.32)$ & $78.75(75.63)$ & $17.68(16.33)$ \\
\cline { 2 - 6 } & Forward & $1.00(1.01)$ & $22.72(22.14)$ & $63.02(62.81)$ & $14.45(14.05)$ \\
\hline
\end{tabular}


Interestingly, the obtaining of the maximum PCE with the molecular carbazole HTMs (DM1 and DM2) required a rather long light soaking. The first measurements gave low PCEs. However, with time, this parameter continuously increased before to stabilize as illustrated in Figure 8.
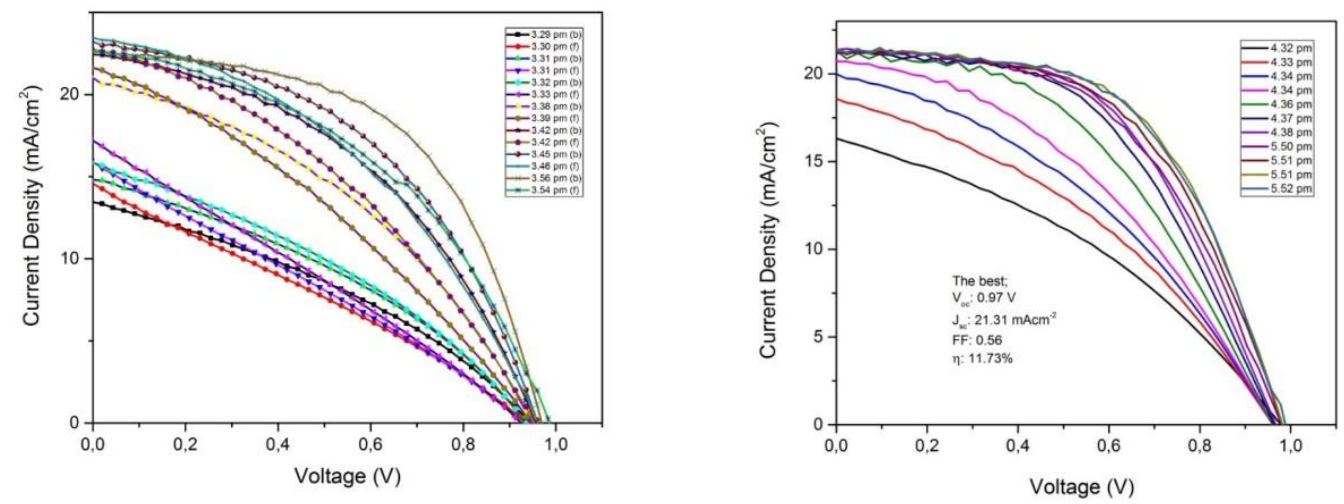

Figure 8. Effect of light soaking of DM1 and DM2 PSCs

The photovoltaic parameters provided in Table 2 are the stabilized ones. This light soaking effect was not observed for the polymer DM1P. We explain it by the low $\mathrm{T}_{\mathrm{g}}$ of pristine molecular HTMs $\left(\mathrm{T}_{\mathrm{g}}\right.$ bellow $75^{\circ} \mathrm{C}$ ). The presence of additives in the HTM (tert butylpyrridine and LiTFSI) even lower these $\mathrm{T}_{\mathrm{g}}{ }^{41}$ Under continuous light irradiation, the cells were heated. It conducted to morphological change of the HTL, to an improvement of the HTM/Perovskite interface and thus ameliorated the photovoltaic efficiency. In contrast, DM1P has a much higher $\mathrm{T}_{\mathrm{g}}\left(186^{\circ} \mathrm{C}\right)$ and is morphologically stable at the operating temperature. Its amorphous nature ensures a good HTL/perovskite interface during the continuous light irradiation.

\section{Conclusion}

We have reported three novel carbazole-based molecular and polymeric materials. These compounds have thermal, morphological, optical and electrochemical properties suitable for an application in perovskite based photovoltaic devices. While their optoelectrochemical properties are nearly identical, the thermal properties differ in a large extent between the monomer and its corresponding polymer. These materials have the same photovoltaic performances, the polymeric HTM has led to more stable devices. This illustrates the higher thermal stability of polymeric HTM versus its corresponding monomer. 


\section{Acknowledgements}

M.U. and D.M. acknowledge the Indonesia Endowment Fund for Education (LPDP) and the Mexican government for their $\mathrm{PhD}$ scholarship, respectively.

\section{Reference}

(1) Calió, L.; Momblona, C.; Gil-Escrig, L.; Kazim, S.; Sessolo, M.; Sastre-Santos, Á.; Bolink, H. J.; Ahmad, S. Vacuum Deposited Perovskite Solar Cells Employing Dopant-Free Triazatruxene as the Hole Transport Material. Sol. Energy Mater. Sol. Cells 2017, 163, 237-241. https://doi.org/10.1016/j.solmat.2017.01.037.

(2) Bui, T.-T.; Shah, S. K. S. K.; Abbas, M.; Sallenave, X.; Sini, G.; Hirsch, L.; Goubard, F. Carbazole-Based Molecular Glasses as Hole-Transporting Materials in Solid State DyeSensitized Solar Cells. ChemNanoMat 2015, 1 (3), 203-210. https://doi.org/10.1002/cnma.201500014.

(3) Bui, T.-T.; Goubard, F. Recent Advances in Small Molecular, Non-Polymeric Organic Hole Transporting Materials for Solid-State DSSC. EPJ Photovoltaics 2013, 4, 40402. https://doi.org/10.1051/epjpv/2013024.

(4) Bui, T. T.; Beouch, L.; Sallenave, X.; Goubard, F. Carbazol-N-Yl and Diphenylamino EndCapped Triphenylamine-Based Molecular Glasses: Synthesis, Thermal, and Optical Properties. Tetrahedron Lett. 2013, 54 (32), 4277-4280.

(5) Xue, Y.; Wu, Y.; Li, Y. Readily Synthesized Dopant-Free Hole Transport Materials with Phenol Core for Stabilized Mixed Perovskite Solar Cells. J. Power Sources 2017, 344, 160-169. https://doi.org/10.1016/j.jpowsour.2017.01.121.

(6) Al Mousawi, A.; Lara, D. M.; Noirbent, G.; Dumur, F.; Toufaily, J.; Hamieh, T.; Bui, T.-T.; Goubard, F.; Graff, B.; Gigmes, D.; et al. Carbazole Derivatives with Thermally Activated Delayed Fluorescence Property as Photoinitiators/Photoredox Catalysts for LED 3D Printing Technology. Macromolecules 2017, 50 (13), 4913-4926. https://doi.org/10.1021/acs.macromol.7b01114.

(7) Al Mousawi, A.; Dumur, F.; Garra, P.; Toufaily, J.; Hamieh, T.; Goubard, F.; Bui, T.-T.; Graff, B.; Gigmes, D.; Pierre Fouassier, J.; et al. Azahelicenes as Visible Light Photoinitiators for Cationic and Radical Polymerization: Preparation of Photoluminescent Polymers and Use in High Performance LED Projector 3D Printing Resins. J. Polym. Sci. Part A Polym. Chem. 2017, 55 (7), 1189-1199. https://doi.org/10.1002/pola.28476. 
(8) Bui, T.-T.; Goubard, F.; Ibrahim-Ouali, M.; Gigmes, D.; Dumur, F. Thermally Activated Delayed Fluorescence Emitters for Deep Blue Organic Light Emitting Diodes: A Review of Recent Advances. Appl. Sci. 2018, 8 (4), 494. https://doi.org/10.3390/app8040494.

(9) Bui, T.-T.; Goubard, F.; Ibrahim-Ouali, M.; Gigmes, D.; Dumur, F. Recent Advances on Organic Blue Thermally Activated Delayed Fluorescence (TADF) Emitters for Organic LightEmitting Diodes (OLEDs). Beilstein J. Org. Chem. 2018, 14 (1), 282-308. https://doi.org/10.3762/bjoc.14.18.

(10) Sathiyan, G.; Sivakumar, E. K. T.; Ganesamoorthy, R.; Thangamuthu, R.; Sakthivel, P. Review of Carbazole Based Conjugated Molecules for Highly Efficient Organic Solar Cell Application. Tetrahedron Lett. 2016, 57 (3), 243-252. https://doi.org/10.1016/j.tetlet.2015.12.057.

(11) Di Giacomo, F.; Zardetto, V.; D’Epifanio, A.; Pescetelli, S.; Matteocci, F.; Razza, S.; Di Carlo, A.; Licoccia, S.; Kessels, W. M. M.; Creatore, M.; et al. Flexible Perovskite Photovoltaic Modules and Solar Cells Based on Atomic Layer Deposited Compact Layers and UV-Irradiated $\mathrm{TiO}_{2}$ Scaffolds on Plastic Substrates. Adv. Energy Mater. 2015, 5 (8), 1401808. https://doi.org/10.1002/aenm.201401808.

(12) Kim, H. S.; Jang, I. H.; Ahn, N.; Choi, M.; Guerrero, A.; Bisquert, J.; Park, N. G. Control of I-V Hysteresis in CH3NH3PbI3 Perovskite Solar Cell. J. Phys. Chem. Lett. 2015, 6 (22), 4633-4639. https://doi.org/10.1021/acs.jpclett.5b02273.

(13) Ulfa, M.; Zhu, T.; Goubard, F.; Pauporté, T. Molecular versus Polymeric Hole Transporting Materials for Perovskite Solar Cell Application. J. Mater. Chem. A 2018, 6 (27), 13350-13358. https://doi.org/10.1039/C8TA03875A.

(14) Hsu, C.-Y.; Chen, Y.-C.; Lin, R. Y.-Y. Solid-State Dye-Sensitized Solar Cells Based on Spirofluorene (Spiro-OMeTAD) and Arylamines as Hole Transporting Materials. Phys. Chem. Chem. Phys. 2012, 14 (41), 14099. https://doi.org/10.1039/c2cp41326d.

(15) Holliday, S.; Donaghey, J. E.; McCulloch, I. Advances in Charge Carrier Mobilities of Semiconducting Polymers Used in Organic Transistors. Chem. Mater. 2014, 26 (1), 647-663. https://doi.org/10.1021/cm402421p.

(16) Arias, A. C.; MacKenzie, J. D.; McCulloch, I.; Rivnay, J.; Salleo, A. Materials and Applications for Large Area Electronics: Solution-Based Approaches. Chem. Rev. 2010, 110 (1), 3-24. https://doi.org/10.1021/cr900150b.

(17) Zaumseil, J.; Sirringhaus, H. Electron and Ambipolar Transport in Organic Field-Effect Transistors. Chem. Rev. 2007, 107 (4), 1296\$1323. https://doi.org/10.1021/CR0501543.

(18) Bui, T.-T.; Shah, S. K.; Sallenave, X.; Abbas, M.; Sini, G.; Hirsch, L.; Goubard, F. Di(p- 
Methoxyphenyl)Amine End-Capped Tri(p-Thiophenylphenyl)Amine Based Molecular Glasses as Hole Transporting Materials for Solid-State Dye-Sensitized Solar Cells. RSC Adv. 2015, 5 (61), 49590-49597. https://doi.org/10.1039/c5ra07226c.

(19) Bui, T.-T.; Goubard, F.; Troughton, J.; Watson, T. Simple 3,6-Bis(Diphenylaminyl)Carbazole Molecular Glasses as Hole Transporting Materials for Hybrid Perovskite Solar Cells. J. Mater. Sci. Mater. Electron. 2017, 28 (23), 17551-17556. https://doi.org/10.1007/s10854-017-7691-y. (20) Cho, A.-N.; Kim, H.-S.; Bui, T.-T.; Sallenave, X.; Goubard, F.; Park, N.-G. Role of LiTFSI in High Tg Triphenylamine-Based Hole Transporting Material in Perovskite Solar Cell. RSC Adv. 2016, 6 (72), 68553-68559. https://doi.org/10.1039/c6ra12574c.

(21) Daskeviciene, M.; Paek, S.; Wang, Z.; Malinauskas, T.; Jokubauskaite, G.; Rakstys, K.; Cho, K. T.; Magomedov, A.; Jankauskas, V.; Ahmad, S.; et al. Carbazole-Based Enamine: Low-Cost and Efficient Hole Transporting Material for Perovskite Solar Cells. Nano Energy 2017, 32, 551557. https://doi.org/10.1016/j.nanoen.2017.01.015.

(22) Rakstys, K.; Paek, S.; Gao, P.; Gratia, P.; Marszalek, T.; Grancini, G.; Cho, K. T.; Genevicius, K.; Jankauskas, V.; Pisula, W.; et al. Molecular Engineering of Face-on Oriented Dopant-Free Hole Transporting Material for Perovskite Solar Cells with 19\% PCE. J. Mater. Chem. A 2017, 5 (17), 7811-7815. https://doi.org/10.1039/C7TA01718A.

(23) Zhang, M.-D.; Zheng, B.-H.; Zhuang, Q.-F.; Huang, C.-Y.; Cao, H.; Chen, M.-D.; Wang, B. Two Dimethoxyphenylamine-Substituted Carbazole Derivatives as Hole-Transporting Materials for Efficient Inorganic-Organic Hybrid Perovskite Solar Cells. Dye. Pigment. 2017, 146, 589595. https://doi.org/10.1016/J.DYEPIG.2017.07.037.

(24) Zhao, X.; Wang, M. Organic Hole-Transporting Materials for Efficient Perovskite Solar Cells. Mater. Today Energy 2018, 7, 208-220. https://doi.org/10.1016/j.mtener.2017.09.011.

(25) Berton, N.; Nakar, R.; Schmaltz, B. DMPA-Containing Carbazole-Based Hole Transporting Materials for Perovskite Solar Cells: Recent Advances and Perspectives. Synthetic Metals. Elsevier Ltd June 1, 2019, pp 91-106. https://doi.org/10.1016/j.synthmet.2019.04.004.

(26) Torres, A.; Rego, L. G. C. Surface Effects and Adsorption of Methoxy Anchors on Hybrid Lead Iodide Perovskites: Insights for Spiro-MeOTAD Attachment. J. Phys. Chem. C 2014, 118 (46), 26947-26954. https://doi.org/10.1021/jp510595s.

(27) Bui, T.-T.; Ulfa, M.; Maschietto, F.; Ottochian, A.; Nghiêm, M.-P.; Ciofini, I.; Goubard, F.; Pauporté, T. Design of Dendritic Core Carbazole-Based Hole Transporting Materials for Efficient and Stable Hybrid Perovskite Solar Cells. Org. Electron. 2018, 60, 20-30. https://doi.org/10.1016/j.orgel.2018.05.024. 
(28) Ulfa, M.; Pauporte, T.; Bui, T.-T.; Goubard, F. Impact of Organic Hole Transporting Material and Doping on the Electrical Response of Perovskite Solar Cells. J. Phys. Chem. C 2018, 122 (22), 11651-11658. https://doi.org/10.1021/acs.jpcc.8b02141.

(29) Abdallah, M.; Magaldi, D.; Hijazi, A.; Graff, B.; Dumur, F.; Fouassier, J.; Bui, T.; Goubard, F.; Lalevée, J. Development of New High-Performance Visible Light Photoinitiators Based on Carbazole Scaffold and Their Applications in 3D Printing and Photocomposite Synthesis. J. Polym. Sci. Part A Polym. Chem. 2019, 10.1002/pola.29471. https://doi.org/10.1002/pola.29471.

(30) Konishi, A.; Yoda, N.; Marvel, C. S. Base-Catalyzed Polymerization of p-Styrenesulfonamides. II. N-Methyl and N-Phenyl Derivatives. J. Polym. Sci. Part A Gen. Pap. 1965, 3 (11), 38333842. https://doi.org/10.1002/pol.1965.100031114.

(31) Jenkins, A. D.; Jones, R. G.; Moad, G. Terminology for Reversible-Deactivation Radical Polymerization Previously Called "Controlled” Radical or "Living” Radical Polymerization (IUPAC Recommendations 2010). Pure Appl. Chem. 2009, 82 (2), 483-491. https://doi.org/10.1351/PAC-REP-08-04-03.

(32) Mayo, F. R. Chain Transfer in the Polymerization of Styrene: The Reaction of Solvents with Free Radicals ${ }^{1}$. J. Am. Chem. Soc. 1943, 65 (12), 2324-2329. https://doi.org/10.1021/ja01252a021.

(33) Flory, P. J. The Mechanism of Vinyl Polymerizations. J. Am. Chem. Soc. 1937, 59 (2), 241-253. https://doi.org/10.1021/ja01281a007.

(34) Furuncuoğlu, T.; Uğur, I.; Degirmenci, I.; Aviyente, V. Role of Chain Transfer Agents in Free Radical Polymerization Kinetics. Macromolecules 2010, 43 (4), 1823-1835. https://doi.org/10.1021/ma902803p.

(35) Matyjaszewski, K.; Davis, T. P. Handbook of Radical Polymerization; 2002; Vol. 125. https://doi.org/10.1002/0471220450.

(36) Frisch, M. J.; Trucks, G. W.; Schlegel, H. B.; Scuseria, G. E.; Robb, M. A.; Cheeseman, J. R.; Scalmani, G.; Barone, V.; Mennucci, B.; Petersson, G. A.; et al. Gaussian, Inc., Wallingford CT. Gaussian, Inc., Wallingford CT. 2009, 2009.

(37) Chai, J. Da; Head-Gordon, M. Long-Range Corrected Hybrid Density Functionals with Damped Atom-Atom Dispersion Corrections. Phys. Chem. Chem. Phys. 2008, 10 (44), 6615-6620. https://doi.org/10.1039/b810189b.

(38) Pommerehne, J.; Vestweber, H.; Guss, W.; Mahrt, R. F.; Bässler, H.; Porsch, M.; Daub, J. Efficient Two Layer Leds on a Polymer Blend Basis. Adv. Mater. 1995, 7 (6), 551-554. https://doi.org/10.1002/adma.19950070608. 
(39) Cardona, C. M.; Li, W.; Kaifer, A. E.; Stockdale, D.; Bazan, G. C. Electrochemical Considerations for Determining Absolute Frontier Orbital Energy Levels of Conjugated Polymers for Solar Cell Applications. Adv. Mater. 2011, 23 (20), 2367-2371. https://doi.org/10.1002/adma.201004554.

(40) Wang, P.; Ulfa, M.; Pauporté, T. Effects of Perovskite Monovalent Cation Composition on the High and Low Frequency Impedance Response of Efficient Solar Cells. J. Phys. Chem. C 2018, 122 (4), 1973-1981. https://doi.org/10.1021/acs.jpcc.7b11010.

(41) Zhao, X.; Kim, H. S.; Seo, J. Y.; Park, N. G. Effect of Selective Contacts on the Thermal Stability of Perovskite Solar Cells. ACS Appl. Mater. Interfaces 2017, 9 (8), 7148-7153. https://doi.org/10.1021/acsami.6b15673. 